\title{
Cancer incidence in Swedish sterilant workers exposed to ethylene oxide
}

\author{
Lars Hagmar, Zoli Mikoczy, Hans Welinder
}

Department of Occupational and Environmental Medicine, University Hospital, S-221 85 Lund, Sweden

L Hagmar

Z Mikoczy

$\mathrm{H}$ Welinder

Correspondence to: Dr L Hagmar, Department of Occupational and Environmental and

Unvironmentity Hospital, S-221 85 Lund, Sweden.

Accepted 28 October 1994

\begin{abstract}
Objectives-To assess the risk of cancer, especially leukaemia, in a cohort of sterilant workers exposed to ethylene oxide (EtO).

Methods-A cohort of 2170 workers employed for at least one year in two plants that produce disposable medical equipment sterilised with EtO has previously been established. The results of an update with four more years of observation are presented. The cancer incidence was assessed for the periods 1976 to 1990 and 1972 to 1990 and cause specific standardised incidence ratios (SIRs) were calculated. Individual cumulative exposure to EtO, expressed as ppm-years, was estimated and used in exposure-response analyses.
\end{abstract}

Results-Six lymphohaematopoietic tumours were observed (SIR 1.78, 95\% confidence interval (95\% CI) 0.65-3.88), of which two were leukaemias (SIR 2.44; 95\% CI 0.30-8.81). When those with cumulative exposures to EtO below the median value $(0.13 \mathrm{ppm}$-years) were excluded, and a minimum of 10 years induction latency period was applied, the incidence ratio for leukaemia increased further (SIR 7.14, 95\% CI 0.87-25.8), but was still not significantly enhanced.

Conclusions-The risk estimate for leukaemia increased, but non-significantly, with time since start of exposure, and with cumulative exposures to EtO above the median value. The subjects with leukaemia had, however, only slightly higher cumulative exposure estimates for EtO than the average cohort member. Nevertheless, the present results may add some minor evidence for an association between EtO and an increased risk of leukaemia.

(Occup Environ Med 1995;52:154-156)
Table 1 Calendar year of first exposure, duration of employment from start of exposure up to 1985, and cumulative exposure to EtO in the cohort of 2170 workers

\begin{tabular}{clcc}
\hline Percentile & $\begin{array}{l}\text { Calendar year of } \\
\text { first exposure }\end{array}$ & $\begin{array}{l}\text { Duration of employment } \\
(y)\end{array}$ & $\begin{array}{l}\text { Cummulative exposure to } \\
\text { EtO (ppm-years) }\end{array}$ \\
\hline 1 st & 1964 & $1 \cdot 0$ & $0 \cdot 02$ \\
10 th & 1972 & $1 \cdot 5$ & 0.04 \\
25 th & 1975 & $2 \cdot 6$ & $0 \cdot 07$ \\
50 th & 1978 & $5 \cdot 6$ & $0 \cdot 13$ \\
75 th & 1980 & $8 \cdot 7$ & $0 \cdot 21$ \\
90 th & 1983 & $11 \cdot 8$ & $1 \cdot 17$ \\
100 th & 1985 & $21 \cdot 9$ & 357 \\
\hline
\end{tabular}

Keywords: cohort study; ethylene oxide; leukaemia

A recent meta-analysis of 10 cohort studies of workers exposed to ethylene oxide (EtO) provided no consistent evidence of an increased risk of leukaemia, ${ }^{1}$ despite the high risk estimates reported in the three small initial studies. ${ }^{2}$ The meta-analysis had, however, a limited statistical power for evaluating a moderate or low excess of risk, due to the low spontaneous rate of leukaemia together with relatively short follow up times in most of the studies. There is thus a need for further epidemiological data to facilitate a more conclusive evaluation. The importance of this is emphasised by the fact that EtO is a direct acting epoxide and an alkylating agent, which is mutagenic in mammalian cell systems, is an animal carcinogen, and has induced cytogenetic damage in exposed workers. Moreover, the annual world production of EtO is $>5.5$ million tonnes. ${ }^{3}$ Thus even if airborne EtO has been reduced in occupational settings during the past decades, a substantial number of workers are still exposed.

We have updated a cohort study of Swedish sterilant workers exposed to EtO with four more years of observation. The initial results from this study ${ }^{4}$ were included in the metaanalysis mentioned above. ${ }^{1}$

\section{Material and methods}

The cohort comprised 2170 workers (1309 women and 861 men), employed for at least one year before 1986, in two plants that produced disposable medical equipment sterilised with EtO. ${ }^{4}$ The sterilisation was started in 1970 in plant $A$ with a 1:1 mixture of EtO and methyl formate. The process and exposure assessments have been described in detail previously. ${ }^{4}$ From initial exposures in 1970 as high as about $40 \mathrm{ppm}$ there had been a continuous decrease of exposure. Since 1985 only the sterilisers have had eight hour time weighted exposures $>0.2 \mathrm{ppm}$. In plant $B$ the sterilisation process started in 1964 and used a 1:1 EtO:methyl formate mixture which was replaced in 1978 by an EtO:carbon dioxide mixture. From initial exposures in 1964 as high as about $75 \mathrm{ppm}$, there was a continuous decrease of exposure. Since 1985, only the sterilisers and store workers have had eight hour time weighted exposures $>0.2 \mathrm{ppm}$.

Up to 1973 the sterilisers were exposed to very high concentrations when unloading the autoclaves for 30 minutes a day. These peak exposures have been estimated to be about 500-1000 ppm. After 1975 there have been 
Table 2 Vital status on 31 December 1990 in the cohort of workers exposed to $\mathrm{EtO}$

\begin{tabular}{llcc}
\hline Vital status & $\begin{array}{l}\text { Plant } A \\
n(\%)\end{array}$ & $\begin{array}{l}\text { Plant } B \\
n(\%)\end{array}$ & $\begin{array}{l}\text { Total } \\
n(\%)\end{array}$ \\
\hline Living & $1099(95 \cdot 5)$ & $978(96 \cdot 0)$ & $2077(95 \cdot 7)$ \\
Dead & $16(1 \cdot 4)$ & $14(1 \cdot 4)$ & $30(1 \cdot 4)$ \\
Emigrated & $36(3 \cdot 1)$ & $27(2 \cdot 6)$ & $63(2 \cdot 9)$ \\
Total & $1151(100 \cdot 0)$ & $1019(100 \cdot 0)$ & $2170(100 \cdot 0)$ \\
\hline
\end{tabular}

short times of peak exposure at a much lower level at the opening of the autoclaves after sterilisation. Individual cumulative exposure to EtO (ppm-years) has been calculated, ${ }^{4}$ and the median value in the cohort was 0.13 ppm-years (table 1). The median calendar year of start of exposure was 1978, and the median duration of employment from start of exposure up to 1985 was $5 \cdot 6$ years.

Vital status in the cohort, which comprised 2170 workers (1309 women and 861 men), was determined on 31 December 1990 (table 2). Nobody was lost in follow up. Thirteen per cent of the cohort consisted of subjects with direct exposure to EtO (sterilisers, development engineers, packers, laboratory technicians, repair men, and store workers) whereas the rest had been indirectly exposed through recirculation of EtO from the air outlets of the autoclaves to the air inlets of the factory.

Table 3 Observed and expected cancer incidence 1972-90* in a cohort of workers exposed to EtO (calculations are based on 2170 subjects and 24851 person-years, and on 1649 subjects and 7326 person-years when a minimum of 10 years induction latency period was applied)

\begin{tabular}{|c|c|c|c|c|c|c|c|c|c|}
\hline \multirow[b]{2}{*}{ Tumour site } & \multirow[b]{2}{*}{$I C D-7$} & \multicolumn{4}{|c|}{ No induction latency period } & \multicolumn{4}{|c|}{$\geqslant 10$ years induction latency period } \\
\hline & & $O$ & $E$ & SIR & $95 \% C I$ & $O$ & $E$ & SIR & $95 \% C I$ \\
\hline Stomach & 151 & 0 & $0 \cdot 81$ & 0 & $0.00-4.55$ & 0 & 0.44 & 0 & $0.00-8 \cdot 38$ \\
\hline & & 3 & 2.05 & $1 \cdot 46$ & $0.30-4.28$ & 3 & 1.07 & $2 \cdot 80$ & $0.58-8 \cdot 19$ \\
\hline Pancreas & 157 & 2 & 0.81 & $2 \cdot 47$ & $0.30-8.92$ & 1 & 0.45 & $2 \cdot 22$ & $0.06-12.4$ \\
\hline Lung & $162-164$ & 2 & $2 \cdot 51$ & $0 \cdot 80$ & $0 \cdot 10-2 \cdot 88$ & 2 & $1 \cdot 45$ & $1 \cdot 38$ & $0 \cdot 17-4.98$ \\
\hline Breast & 170 & 5 & $10 \cdot 8$ & 0.46 & $0.15-1.08$ & 2 & $5 \cdot 54$ & 0.36 & $0.04-1 \cdot 30$ \\
\hline Cervix uteri & 171 & 5 & $2 \cdot 86$ & 1.75 & $0.57-4.08$ & 2 & 0.97 & 2.06 & $0.25-7.45$ \\
\hline Prostate & 177 & 2 & 0.90 & $2 \cdot 22$ & $0.27-8.03$ & 2 & 0.64 & $3 \cdot 13$ & $0 \cdot 38-11 \cdot 3$ \\
\hline Urinary bladder & 181.0 & $\overline{1}$ & $1 \cdot 20$ & 0.83 & $0.02-4.64$ & 0 & 0.65 & & $0.00-5.68$ \\
\hline Melanoma & 190 & 2 & 3.85 & 0.52 & $0.06-1.88$ & 0 & $1 \cdot 78$ & & $0.00-2.07$ \\
\hline Brain & 193.0 & 4 & $2 \cdot 36$ & 1.69 & $0 \cdot 46-4.34$ & 3 & 1.07 & $2 \cdot 80$ & $0.58-8.19$ \\
\hline $\begin{array}{l}\text { Lympho- } \\
\text { haematopoietic } \\
\text { tumours }\end{array}$ & $200-209$ & 6 & $3 \cdot 37$ & $1 \cdot 7$ & $0 \cdot 65-3 \cdot 88$ & 3 & 1.51 & 1.99 & $0.41-5.81$ \\
\hline $\begin{array}{l}\text { Non-Hodgkin's } \\
\text { lymphoma }\end{array}$ & 200,202 & 2 & $1 \cdot 25$ & $1 \cdot 60$ & $0 \cdot 19-5 \cdot 78$ & 0 & 0.63 & 0 & $0 \cdot 00-5 \cdot 86$ \\
\hline $\begin{array}{l}\text { Hodgkin's } \\
\text { lymphoma }\end{array}$ & 201 & 0 & $0 \cdot 73$ & 0 & $0.00-5.05$ & 0 & $0 \cdot 21$ & 0 & $0 \cdot 00-17 \cdot 6$ \\
\hline $\begin{array}{l}\text { Multiple } \\
\text { myeloma }\end{array}$ & 203 & 1 & $0 \cdot 29$ & $3 \cdot 45$ & $0 \cdot 09-19 \cdot 2$ & 1 & $0 \cdot 17$ & $5 \cdot 88$ & $0 \cdot 15-32 \cdot 8$ \\
\hline Leukaemia & $204-205$ & 2 & 0.82 & $2 \cdot 44$ & $0 \cdot 30-8 \cdot 81$ & 2 & 0.36 & $5 \cdot 56$ & $0 \cdot 67-20 \cdot 1$ \\
\hline All & 140-209 & 40 & $46 \cdot 28$ & 0.86 & $0 \cdot 62-1 \cdot 19$ & 22 & $22 \cdot 6$ & 0.97 & $0.62-1.49$ \\
\hline
\end{tabular}

*The follow up period was $1976-90$ for the 1151 subjects from plant $A$.

Table 4 Observed and expected cancer incidence 1972-90 among those 930 subjects with at least $0.14 \mathrm{ppm}$-years of cumulative exposure to $\mathrm{EtO}$ (a minimum of 10 years induction latency period was applied); the calculations were based on 5139 person-years

\begin{tabular}{|c|c|c|c|c|c|}
\hline Tumour site & $I C D-7$ & $O$ & $E$ & $S I R$ & $95 \% C I$ \\
\hline $\begin{array}{l}\text { Colon } \\
\text { Pancreas } \\
\text { Prostate } \\
\text { Brain } \\
\text { Non-Hodgkin's lymphoma } \\
\text { Leukaemia }\end{array}$ & $\begin{array}{l}153 \\
157 \\
177 \\
193 \cdot 0 \\
200,202 \\
204-205\end{array}$ & $\begin{array}{l}3 \\
1 \\
2 \\
3 \\
0 \\
2\end{array}$ & $\begin{array}{l}0.84 \\
0.35 \\
0.51 \\
0.79 \\
0.49 \\
0 \cdot 28\end{array}$ & $\begin{array}{l}3 \cdot 57 \\
2 \cdot 86 \\
3 \cdot 92 \\
3 \cdot 80 \\
0 \cdot 00 \\
7 \cdot 14\end{array}$ & $\begin{array}{l}0 \cdot 74-10 \cdot 4 \\
0 \cdot 07-15 \cdot 9 \\
0 \cdot 47-14 \cdot 2 \\
0 \cdot 78-11 \cdot 1 \\
0 \cdot 00-7 \cdot 53 \\
0 \cdot 87-25 \cdot 8\end{array}$ \\
\hline All & $140-209$ & 22 & 16.95 & $1 \cdot 30$ & $0.83-1.99$ \\
\hline
\end{tabular}

Information on malignant tumours (coded according to the International Classification of Diseases 7 th revision (ICD-7)) diagnosed from 1972 to 1990 was obtained from the National Swedish Tumour Registry. Expected cancer incidences for the periods 1976 to 1990 (cohort A) and 1972 to 1990 (cohort B) were calculated with calendar year, site, sex, and five year age group specific rates for inhabitants in the county. Date of death or emigration, date of diagnosis of a second tumour, or 31 December 1990 were used as individual end points, whichever occurred first. The median follow up time in the cohort was 11.8 years (10th percentile 6.3 , 90th percentile 15.7). Cause specific standardised incidence ratios (SIRs) and $95 \%$ confidence intervals (95\% CIs) were calculated according to the Poisson distribution, or to the $\chi^{2}$ distribution if the expected values were $>10$.

\section{Results}

Table 3 shows that 40 malignant tumours were observed, compared with 46.3 expected (SIR 0.86, 95\% CI 0.62-1.19). Six of them were lymphohaematopoietic (SIR 1.78, 95\% CI 0.65-3.88). More specifically, two cases of leukaemia (chronic myeloid and chronic lymphatic; SIR 2.44; $95 \%$ CI 0.30-8.81), two non-Hodgkin's lymphoma (SIR 1.60, 95\% CI 0.19-5.78), one multiple myeloma (SIR $3.45,95 \%$ CI $0.09-19 \cdot 2$ ), and one case of polycythaemia vera were observed. Nonsignificantly increased incidence ratios, based on very few cases, were also observed for brain tumours (SIR 1.69, 95\% CI 0.46-4.34), pancreatic cancer (SIR 2.47, 95\% CI 0.30-8.92), prostate cancer (SIR 2.22, 95\% CI 0.27-8.03), cervical cancer (SIR 1.75, 95\% CI 0.57-4.08), and colon cancer (SIR $1 \cdot 46,95 \%$ CI $0 \cdot 30-4 \cdot 28)$.

With a minimum 10 year induction latency period, both cases of leukaemia remained and the point estimate of the incidence ratio increased somewhat (SIR 5.56, 95\% CI $0 \cdot 67-20 \cdot 1)$. On the other hand, both cases of non-Hodgkin's lymphoma were excluded. Three out of four brain tumours remained, which increased the incidence ratio further (SIR $2 \cdot 80$ ) but it was still not significantly enhanced (95\% CI 0.58-8 19). A further, but still non-significant, increase in the incidence ratio was found for colon cancer and prostate cancer, but not pancreatic cancer.

When those with cumulative exposure to EtO below the median value $(0 \cdot 13 \mathrm{ppm}-$ years) were excluded and a minimum 10 year induction latency period was applied, the

Table 5 Cumulative exposure estimates for $E t O$ (ppmyears) for some cancer diagnoses

\begin{tabular}{lllll}
\hline & \multicolumn{4}{l}{ Case } \\
\cline { 2 - 5 } Tumour & 1 & 2 & 3 & 4 \\
\hline Brain cancer & $0 \cdot 11$ & 0.21 & $0 \cdot 28$ & $227 \cdot 4$ \\
Non-Hodgkin's lymphoma & 0.09 & 0.18 & - & - \\
Leukaemia & 0.15 & 0.28 & - & - \\
\hline
\end{tabular}


incidence ratio for leukaemia increased further (SIR 7·14, 95\% CI 0.87-25.8; table 4). This was true also for brain cancer (SIR 3.80, 95\% CI 0.78-11.1), and colon cancer (SIR $3.57,95 \%$ CI $0 \cdot 74-10 \cdot 4)$. Table 5 shows the estimated cumulative EtO doses for some of the diagnoses.

\section{Discussion}

Since the previous follow up of this cohort, two cases of leukaemia have been diagnosed. The risk estimate for leukaemia increased with time since start of exposure, but with those who had a cumulative exposure to EtO below the median excluded was still nonsignificant. The subjects with leukaemia had, however, only slightly higher cumulative exposure estimates for EtO than the average cohort member. Nevertheless, the present results may add some minor evidence for an association between $\mathrm{EtO}$ and an increased risk of leukaemia. ${ }^{1}$

There were two main limitations of our present study. Firstly, only a minority in the cohort have had a high exposure to EtO, as reflected in the cumulative exposure estimates. Secondly, the median follow up time was still short (median 11.8 years), which resulted in relatively few person-years at risk and an inability to assess the influence of a biologically relevant induction latency period. This has been shown by a recent meta-analysis indicating a suggestion that risk of leukaemia increases with time since start of exposure to EtO. ${ }^{1}$ Despite the short follow up time, our present results add further evidence in support of such an association.

Our present study design also had some strengths, despite compromise by methodological limitations. Firstly, only this study and the much larger study from the United States have individual data on cumulative exposure. ${ }^{56}$ Secondly, in the study of sterilant workers, the risk of chemical confounding ought to be substantially lower than in the study of workers who produce and manufacture EtO, especially those involved in the chlorohydrin process. ${ }^{37}$

A numerical, but non-significantly increased risk of non-Hodgkin's lymphoma has been found in several previous studies of workers exposed to EtO, ${ }^{6810}$ and a recent meta-analysis concluded that there might be an association. ${ }^{1}$ Our results did not add much to this conclusion.
Exposure of rats to EtO caused an increased incidence of gliomas in the brain. ${ }^{11}$ It is noteworthy that we observed three brain cancers compared with 0.8 expected (table 3 ), when a minimum of 10 years induction latency period was applied and those with the lowest exposures were excluded. The previous overall epidemiological evidence indicates no association between exposure to EtO and brain cancer. ${ }^{1}$

As there is no previous evidence of any association between exposure to EtO and prostate or colon cancer, the non-significant increases in risk of these diseases, based on only two and three cases, respectively, may tentatively be disregarded as spurious findings.

Inclusion of four more years of follow up to the study doubled the number of incident cancers. ${ }^{4}$ The well founded individual cumulative exposure assessments, in combination with the rising number of expected incident tumours, will later on allow a more conclusive evaluation of the association between exposure to EtO and risk of cancer.

We gratefully acknowledge Ms S Holm, Mr A Persson, and Mr S-B Lindquist for their assistance in providing valid exposure estimates. The project was supported by grants from the Swedish Work Environment Fund, the Swedish Cancer Society, and the Medical Faculty, University of Lund.

1 Shore RE, Gardner MJ, Pannett B. Ethylene oxide: an assessment of the epidemiological evidence on carcinoassessment of the epidemiological evidenc

2 Hogstedt C, Aringer L, Gustavsson A. Epidemiologic support for ethylene oxide as a cancer-causing agent. $\mathscr{F} A M A$ 1986;255:1575-8.

3 Greenberg HL, Ott MG, Shore RE. Men assigned to ethylene oxide production or other ethylene oxide related chemical manufacturing: a mortality study. $\mathrm{Br} \mathcal{F}$ Ind Med 1990;47:221-30.

4 Hagmar L, Welinder H, Lindén K, Attewell R, OstermanGolkar S, Törnqvist M. An epidemiological study of cancer risk among workers exposed to ethylene oxide using hemoglobin adducts to validate environmental exposure assessments. Int Arch Occup Environ Health 1991;63:271-7.

5 Greife A, Hornung R, Stayner L, Steenland K. Development of a model for use in estimating exposure to ethylene oxide in a retrospective cohort mortality study. Scand $\mathcal{F}$ Work Environ Health 1988;14:29-30.

6 Steenland K, Stayner L, Greife A, Halperin W, Hayes R, Hornung $R$, Nowlin $S$. Mortality among workers exposed to ethylene oxide. $N$ Engl $f$ Med 1991;324: 1402-7

7 Hogstedt C, Malmqvist N, Wadman B. Leukemia in workers exposed to ethylene oxide. $\mathscr{F} A M A$ 1979;241: 1132-3.

8 Gardner MJ, Coggon D, Pannett B, Harris EC. Workers exposed to ethylene oxide: a follow up study. $\mathrm{Br} \mathcal{F}$ Ind Med 1990;47:860-5.

9 Bisanti L, Maggini M, Raschetti R, Alegiani S, Ippolito F, Caffari B, et al. Cancer mortality in ethylene oxide workers. Br F Ind Med 1993;50:317-24.

10 Wong O, Trent L. An epidemiological study of workers potentially exposed to ethylene oxide. $\mathrm{Br} \mathcal{F}$ Ind Med potentially exposed

11 International Agency for Research on Cancer. IARC monographs on the evaluation of the carcinogenic risk of chemicals to humans-Ethylene oxide, vol 36. Lyon: IARC, 1985. 